\title{
Resíduos da construÇÃo CIVIL EM SAlVAdor: os CAMINHOS PARA UMA GESTÃo SUSTENTÁVEL
}

\author{
CONSTRUCtion WASTE In Salvador: WAYS to a \\ SUSTAINABLE MANAGEMENT
}

\begin{abstract}
GARDÊNIA OLIVEIRA DAVID DE AZEVEDO
Arquiteta da Companhia de Desenvolvimento Urbano do Estado da Bahia (CONDER). M.Sc. em Engenharia Ambiental Urbana
\end{abstract}

\begin{abstract}
ASHER KIPERSTOK
PhD. Professor Adjunto do Departamento de Engenharia Ambiental da Escola Politécnica/UFBA. Coordenador do Programa de Pós-graduação em Produção Limpa-TECLIM/MEPLIM
\end{abstract}

\section{LUIZ ROBERTo SANTOS MORAES}

PhD. Professor Titular em Saneamento do Departamento de Engenharia Ambiental da Escola Politécnica da Universidade Federal da Bahia/UFBA. Docente do Mestrado em Engenharia Ambiental Urbana, MEAU

Recebido:17/04/05 Aceito: 07/02/06

\section{RESUMO}

O artigo discute o impacto ambiental provocado pela geração crescente de resíduos da construção civil e sua disposição inadequada, analisando a legislação sobre o tema e as possibilidades de sua minimização na cidade do Salvador. Como contribuição, são sugeridas medidas para viabilizar a prevenção da geração de resíduos e é proposto um modelo simplificado de fluxo dos resíduos da construção civil em Salvador, para estimular a redução do desperdício nas obras e, conseqüentemente, menor custo na gestão da cidade e menor impacto ambiental. A partir dessa proposta se obteria uma redução da geração dos RCC de 30\%, um desvio do aterro de inertes de $37,3 \%$ e, ainda, permaneceria seguindo, diretamente, para o aterro $32,7 \%$ dos resíduos totais, não absorvidos na reciclagem ou reutilização.

PALAVRAS-CHAVE: Prevenção da poluição, resíduos da construção civil, minimização de resíduos da construção, geração de resíduos da construção, desvio de resíduos de aterro.

\begin{abstract}
This paper discusses the environmental impacts caused by construction waste generation and its inadequate disposal, analyzing the regulation related to this subject and possibilities for its minimization in the city of Salvador. As a contribution measures are suggested to make viable waste construction prevention. It is proposed a draft model for construction waste streams that stimulates the reduction of losses of building materials in construction sites and, consequently, reduces costs in urban management as well as environmental impacts. This proposal suggests the possibility of a source generation reduction of $30 \%$, a $37 \%$ diversion of materials from landfills and, still, $32.7 \%$ of construction waste generation, not absorbed in the recycling or reuse, remain following, directly, for landfill.
\end{abstract}

KEYWORDS: Pollution prevention, construction and demolition debris, construction waste minimization, construction waste generation, waste diversion from landfill.

\section{INTRODUÇÃO}

O setor da construção civil, responsável por 15 a $50 \%$ do consumo dos recursos naturais (USP, 2003), é certamente o maior gerador de resíduos de toda a sociedade (John e Agopyan, 2003). Além disso, a habitação consome muita energia em todo o seu ciclo-de-vida, conforme pode ser visto na Figura 1, que mostra a maneira como se consome energia no Planeta, cabendo à habitação $50 \%$ da energia consumida.

Praticamente todas as atividades desenvolvidas na construção civil são ge- radoras de resíduos, comumente chamado entulho ou resíduo de construção e demolição (RCD), ou, ainda, como atualmente tem sido denominado, resíduo da construção civil (RCC). No processo construtivo, o alto índice de perdas ${ }^{1}$ é a principal causa do resíduo gerado (Zordan, 2003 citado por Resíduos..., 2003). Segundo Pinto (2003), é aceitável a afirmação de que a perda varia entre 20 e 30\% da massa total de materiais para a construção empresarial (construção residencial em edifícios), a depender do nível tecnológico do construtor. Não foram encontrados registros sobre a inten- sidade das perdas em outros tipos de construção (reformas, autoconstrução, obras viárias) no Brasil.

As estimativas internacionais sobre a geração per capita desse resíduo variam entre 130 e $3.000 \mathrm{~kg} / \mathrm{hab}$.ano. No caso do Brasil, Pinto (2003) apresenta resultados entre 230 a $730 \mathrm{~kg} /$ hab.ano e considera que a massa de RCC gerada nas cidades, muitas vezes, é igual ou maior do que a massa dos resíduos domiciliares - em cidades brasileiras de médio e grande portes, varia entre mais de 45\% (Salvador) a $70 \%$ da massa total dos resíduos sólidos urbanos (RSU) gerados. A Prefei-

\footnotetext{
Quantidade de material não utilizado dentro de uma obra, mas que foi especificado ou comprado, e que pode ser transformada em resíduo ou incorporado ao serviço.
} 


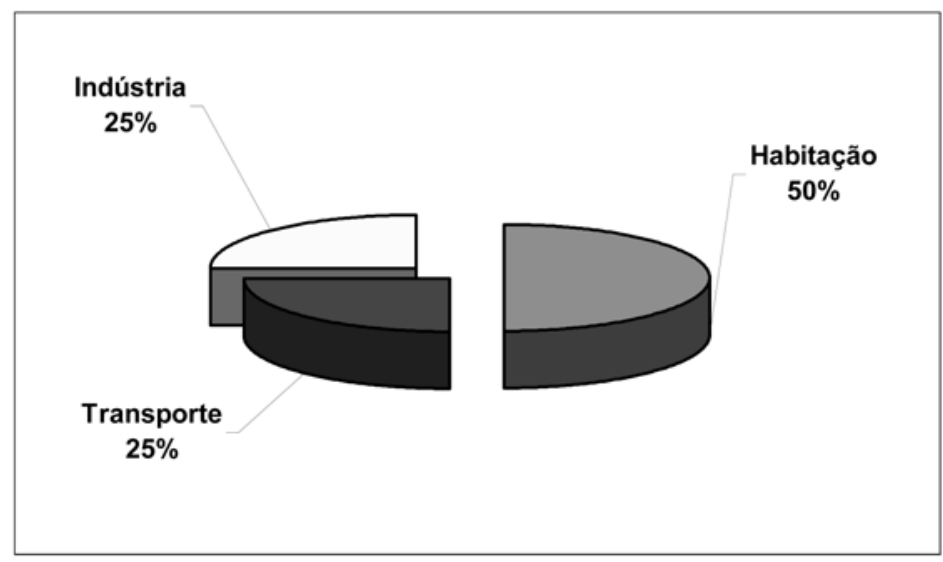

Fonte: Jornadas da Bioconstrução, 1996 apud ADAM, 2001.

Figura I - Consumo energético mundial

tura de São Paulo, que gerencia 40\% dos RCC, tem uma estimativa de 280kg/hab.ano (Resíduos.., 2003).

O problema principal desse tipo de resíduo, do ponto de vista ambiental e até estético, é a sua deposição irregular, incentivando a criação de pontos de lixo. Por outro lado, do ponto de vista financeiro, esse descarte irregular onera as administrações municipais, que acabam tendo de responsabilizar-se pela remoção e disposição desses resíduos acumulados. Isso, segundo John e Agopyan (2003, p. 4), tem-se transformado em um "negócio estabelecido em quase todas as grandes cidades brasileiras, envolvendo as empresas contratadas pela prefeitura para recolher o entulho depositado irregularmente", a um custo médio de $\mathrm{R} \$ 10 /$ hab/ano (transporte e disposição).

Para tornar-se sustentável do ponto de vista ambiental e econômico, a construção deve estar baseada na prevenção e redução dos resíduos gerados, o que pode ser obtido com a aplicação de metodologias de Produção Limpa ${ }^{2}$ durante todo o processo de construção e vida útil de uma edificação.

Este trabalho tem por objetivo avaliar a gestão dos resíduos da construção civil, considerando o enfoque da minimização da geração de resíduos, esboçando a partir daí uma proposta para a cidade do Salvador a luz de uma visão de sustentabilidade ambiental.

\section{É POSSÍVEL A MINIZAÇÃO DOS RESÍDUOS DA CONSTRUÇÃO CIVIL?}

Ao se reconhecer que o Planeta tem uma capacidade de suporte limitada e $^{3}$ que o enfoque do controle da poluição não tem sido suficiente para compatibilizar a demanda humana e a disponibilidade dos recursos naturais, em uma escala ecologicamente sustentável, é que surgem tecnologias que buscam um enfoque de prevenção da poluição e minimização de resíduos, como forma de evitar os desperdícios de matéria-prima e energia, convertidos em resíduos sólidos, líquidos e gasosos, responsáveis por adicionar custos aos processos produtivos e gerar problemas ambientais (Azevedo, 2004).

A geração de resíduo na construção civil pode ocorrer nas diferentes fases do ciclo de vida dos empreendimentos - construção, manutenção e reformas e demolição. $\mathrm{Na}$ fase de construção, a geração está relacionada às perdas nos processos construtivos - parte dessas perdas é incorporada nas construçôes e parte se converte em resíduo (John e Agopyan, 2003). Na fase de manutenção e reformas, está relacionada a açōes corretivas nas edificações, reformas ou modernizações de parte ou de toda a edificação e do descarte de componentes que atingiram o final de sua vida útil.

John e Agopyan (2003) identificam algumas açóes que direcionam para a redução da geração de menos resíduo na construção civil:

- mudanças de tecnologia para combater as perdas;

- aperfeiçoamento e flexibilidade de projeto;

- melhoria da qualidade de construção, de forma a reduzir a manutenção causada pela correção de defeitos;

- seleção adequada de materiais, considerando, inclusive, o aumento da vida útil dos diferentes componentes e da estrutura dos edifícios;

- capacitação de recursos humanos;

- utilização de ferramentas adequadas;

- melhoria da condição de estoque e transporte;

- melhor gestão de processos;

- incentivo para que os proprietários realizem modificações nas edificaçōes e não demoliçōes;

- taxação sobre a geração de resíduos;

- medidas de controle de disposição;

- campanhas educativas.

Ressalta-se, no entanto, que mudanças tecnológicas também podem provocar mais perdas, como é o caso dos revestimentos internos à base de gesso, com perdas de até $120 \%$ no serviço, conforme foi observado por John e Agopyan (2003).

Quando a redução da geração de resíduos não for alcançada, pode-se recorrer a reutilização e reciclagem desses resíduos como solução intermediária. No Brasil, a prática da reciclagem de entulho ainda é pouco difundida. Alguns municípios como Belo Horizonte, São Paulo, Londrina, Porto Alegre, possuem usinas de reciclagem; essas usinas, entretanto, absorvem menos de $10 \%$ dos resíduos urbanos (Johne Agopyan, 2003).

\section{Como se encontra a legislação sobre o tema?}

Mesmo sem uma política nacional de saneamento ambiental, ou mesmo de resíduos sólidos, entrou em vigor, a partir de janeiro de 2003, a Resolução $\mathrm{n}^{\circ} 307 / 02$, de 5 de julho de 2002, do Conselho Nacional de Meio Ambiente (CONAMA), que dispóe sobre a gestão dos resíduos da construção civil, entendendo-se como tal, os resíduos "provenientes de construções, reformas, reparos e demolições de obras de construção civil, e os resultantes da preparação e da escavação de terrenos, tais como: tijolos, blocos cerâmicos, concreto em geral, solos, rochas, metais, resinas, colas, tintas, madeiras e compensados, forros, argamassa, gesso, telhas, pavimento asfáltico, vidros, plásticos, tubulações, fiação elétrica etc., comumente chamados de entulhos de obras, caliça ou metralha” (Brasil, 2003, p. 1). A Resolução estabelece o prazo máximo de 12 meses para que os municípi-

\footnotetext{
Entre as diversas metodologias utilizadas, destacam-se as propostas da USEPA e UNEP/UNIDO/CNTL (Kiperstok, 2002).

${ }^{3}$ Definido como a máxima carga suportável (Carrying Capacity) em um determinado ecossistema. Pode ser expresso em termos de população de uma espécie. Cálculos globais indicam que a humanidade está consumindo acima de um terço a mais do que a natureza pode reproduzir (Thorpe, 1999).
} 
os e o Distrito Federal elaborem seus Planos Integrados de Gerenciamento de Resíduos da Construção Civil, contemplando os pequenos geradores de entulho. Aos grandes geradores foi dado um prazo de dois anos (até janeiro de 2005) para que incluam, nos seus projetos de obras a serem submetidos à aprovação, o projeto de Gerenciamento de Resíduos da Construção Civil (Bonfim, 2003; Brasil, 2003).

Essa Resolução define, para a construção civil, quatro classes de resíduos, que deverão ter tratamentos distintos (Brasil, 2003):

- Classe A - resíduos reutilizáveis ou recicláveis como agregados, tais como tijolo, blocos, telhas, placas de revestimento, argamassa, concreto, tubos, meio-fio, solos de terraplanagem etc;

- Classe B - resíduos recicláveis para outras destinações, tais como plástico, $\mathrm{papel} /$ papelão, metal, madeira etc;

- Classe C - resíduos ainda sem tecnologia ou aplicaçôes economicamente viáveis para a sua reciclagem/recuperação, tais como os produtos oriundos do gesso (tratamento pelo gerador);

- Classe D - perigosos, tais como tintas, solventes, óleos e outros ou aqueles contaminados (tratamento pelo fabricante).

A Resolução CONAMA n ${ }^{\circ}$ 307/02 constitui um avanço, pois disciplina as ações necessárias para minimizar os impactos ambientais, proibindo, inclusive, a disposição dos RCC em aterros de resíduos domiciliares (coisa que atualmente ainda é comum) e em áreas de bota-fora. Ademais, define a responsabilidade das prefeituras em apoiar o pequeno gerador e, como responsabilidade do grande gerador, o controle e manejo dos resíduos, tendo como principal objetivo a sua não geração. Por outro lado, a classificação em tipos diferenciados ajudará o controle e manejo adequado dos resíduos, bem como o melhor reaproveitamento, quando sua geração não puder ser evitada. Cabe, enfim, aos municípios, a partir de agora, imprimir em suas legislaçôes o estímulo à não geração de resíduos como um fator primordial para a solução da questão, evitando o desperdício de recursos naturais, muitas vezes, não renováveis.

Em Salvador, o Projeto de Gestão Diferenciada de Entulho tem como suporte legal o Decreto $\mathrm{n}^{\circ} 12.133$, de
8/10/98 (Salvador, 1998), chamado Regulamento do Entulho ${ }^{4}$, que estabelece a obrigação para o proprietário (seja pessoa física ou jurídica) ou ao responsável legal ou técnico por uma obra de construção civil ou movimento de terra, a obrigação de providenciar, às suas expensas, o transporte de entulho até os locais autorizados para sua recepção, bem como a aquisição dos recipientes adequados para acondicionamento no local da obra. Determina, também, a obrigatoriedade de cadastro para pessoas físicas ou jurídicas que realizam o transporte de entulho no município (Carneiro, Brum e Cassa, 2001), as quais devem cumprir as normas de segurança e levar o material para os locais autorizados. Prevê, ainda, pesadas multas para quem joga entulho nas ruas ou locais não autorizados e para quem transporta entulho sem autorização ou desrespeitando normas de segurança (Salvador, 1998; Santana, 2003).

O Decreto $n^{\circ} 12.133 / 98$ antecipouse à Resolução CONAMA n ${ }^{\circ} .307 / 02$, no que tange a previsão de locais para recepção de resíduos de pequenos e grandes geradores, entretanto, não adota como princípio a prevenção da geração de resíduos e nem estabelece a sua segregação em classes para facilitar o seu reaproveitamento ou armazenamento para posterior utilização.

\section{OS RESÍDUOS DA CONSTRUÇÃO CIVIL EM SALVADOR}

Em 2002, Salvador gerava por dia 2.164t de RCC, ou 655.569t/ano, significando 45,03\% do RSU (Salvador, 2002). A Prefeitura, em 1997, lançou o Projeto de Gestão Diferenciada de Entulho para resolver o problema da disposição inadequada desse resíduo, espalhado por vários pontos na cidade. Foram criados Postos de Descarte de Entulho (PDE), onde o pequeno gerador pode descartar até $2 \mathrm{~m}^{3}$ de material. Para os grandes geradores, existem as denominadas Bases de Descarte de Entulho (BDE) (Salvador, 1997, 1999; Bloisi, 2002).

Quando do início do projeto, foram identificados 220 pontos de descarte clandestino em encostas, terrenos baldios, córregos, valas, praias, estradas, tendo como conseqüência a criação de pontos de lixo, mau cheiro, doenças, obstru- ção do sistema de drenagem, inundações, insegurança no trânsito, deslizamentos e proliferação de insetos e animais nocivos (Salvador, 1997).

A cidade dispunha, em 2002, de três formas de recolhimento (Salvador, 1999):

- pelos próprios geradores, que transportam o resíduo diretamente para o destino final;

- por empresas credenciadas, que cobram pelo serviço e têm permissão da Prefeitura para a coleta e o transporte de resíduos até o aterro;

- pela LIMPURB nos PDE, objetivando reduzir a disposição aleatória.

Em 2002, 55,80\% de RCC foi transportado pela LIMPURB, por meio de empresas terceirizadas. $\mathrm{O}$ gerador do resíduo viabilizou o transporte do restante, sendo que $5,30 \%$ foi coletado e transportado por empresas licenciadas para tal (Tabela 1). A disposição é feita no Aterro Controlado de Canabrava ${ }^{5}$ e é gratuita.

\section{O projeto de gestão diferenciada}

O projeto foi elaborado com base no modelo de descentralização de tratamento e destinação final, com o objetivo de criar uma estrutura para segregar na origem o RCC gerado em Salvador e transformar o descarte clandestino de entulho em disposição correta (Salvador, 1997, 1999; Bloisi, 2002).

Os postos (PDE) deveriam receber, reutilizar ou transferir entulho de pequenos geradores. As bases (BDE) são áreas maiores que poderiam receber, reutilizar, reciclar ou destinar adequadamente o RCC dos grande geradores e dos postos, sem limite da quantidade (Carneiro, Brum e Cassa, 2001).

O projeto tem como meta a implantação de 22 postos e cinco bases, tendo sido projetadas usinas de reciclagem para duas dessas bases. As usinas proporcionarão a redução dos custos de obras públicas, bem como maior oferta de agregado reciclado brita, areia, bica corrida para uso em pavimentação, argamassa, concreto e contenção de encostas (Bloisi, 2002). Cada usina processará cerca de $200 \mathrm{t} / \mathrm{d}$ de entulho, transformando em agregado, que será utilizado para a produção de materiais de construção de baixo custo (Carneiro et al, 2000).

\footnotetext{
${ }^{4}$ Definido como: "Resíduo gerado pelo setor da construção civil, apresenta um alto potencial de reciclagem, com excelentes oportunidades de aproveitamento" (Carneiro et al, 2001). ${ }^{5}$ Passou a ser chamado de Parque Socioambiental de Canabrava, a partir de 2003, integrando projeto de saneamento ambiental, com a interrupção de parte da disposição de resíduos e encerramento de sua vida útil. Vários projetos estão sendo implantados nesse espaço (Farias, 2003 apud Azevedo, 2004). Para Canabrava são destinados os RCC, podas/ feira e os resíduos dos serviços de saúde (Bloisi, 2002 apud Azevedo,2004).
} 
Tabela I - Execução da coleta de RCC em Salvador - 2002

\begin{tabular}{crr}
\hline Executor & \multicolumn{2}{c}{2002} \\
& \multicolumn{1}{c}{$\%$} & \multicolumn{1}{c}{ t/ano } \\
\hline Empresas privadas & 5,30 & 34.770 \\
Gerador & 38,89 & 254.983 \\
LIMPURB & 55,80 & 365.816 \\
Total & 100,00 & 655.569 \\
\hline
\end{tabular}

Fonte: Salvador, 2002

Em 1999, foram implantados seis PDE, aonde chegam, levados voluntariamente pela população, $99,4 \mathrm{t} / \mathrm{dia}(4,6 \%$ do total de RCC coletado), que por não serem ainda aproveitadas, são encaminhadas para disposição em área do Aterro de Canabrava $^{6}$ (Salvador, 1999; Carneiro, Brum e Cassa, 2001; Bloisi, 2002).

\section{As tendências da geração de entulho}

A implantação da coleta diferenciada de entulho em Salvador teve como resultados (Salvador, 2002; Carneiro, Brum e Cassa, 2001):

- redução em $61,66 \%$ do número de pontos de disposição clandestinos, passando de $420 \mathrm{em} 1996$ para $161 \mathrm{em}$ 2000. Em 2002, contudo, foram contabilizados mais de 250 pontos;

- recepção de 99,4t/dia de RCC nos postos em funcionamento;

- aumento da participação de RCC no total dos resíduos coletados com uma média de $2.746 \mathrm{t} / \mathrm{dia}$ ou quase $50 \%$ do resíduo total coletado em Salvador no ano 2000 , embora não abranja a totalidade de RCC gerado na cidade;

- aumento de $1.490 \mathrm{t} /$ dia ou cerca de $119 \%$ de variação na quantidade de entulho coletado entre 1997 e 2000;

- coleta de 508.732 t/ano (2000), realizada pelo próprio gerador, que resultou numa economia de R\$ 10.528.717,00 para a Prefeitura;

- aumento da participação do gerador na coleta e transporte de RCC, evoluindo de 3\% em 1996 para 61\% em 2000 , com redução para $44,2 \%$, em 2002.

Entre 1996 e 2000, o recolhimento de RCC passou de 255.771t/ano para $832.007 \mathrm{t} / \mathrm{ano}$, ou seja, aumentou aproximadamente $225,3 \%$ no período

Fonte: Salvador, 1996, 2002

Fonte: Carneiro et al, 2001
(Azevedo, 2004). A figura 2 apresenta a evolução da participação do entulho em relação à quantidade total de resíduos coletados. O decréscimo verificado a partir daí (chegando a 45,03\% em 2002), pode ser justificado tanto por um maior controle e fiscalização por parte da LIMPURB com relação aos serviços prestados por terceiros, quanto pela desaceleração ocorrida na economia brasileira ${ }^{7}$ com significativos reflexos na construção civil.
A maior parte de RCC de Salvador é composta por restos de concreto e argamassa (53\%), que junto com o material cerâmico e rochas, totaliza $72 \%$. Outra parte significativa, $22 \%$, é composta por solo e areia (Figura 3). O gesso representa $0,2 \%$ do total, estando na figura agregado no item outros (Carneiro et al, 2000).

O RCC, por um lado, representa perda de recursos para o gerador, tanto em materiais desperdiçados como no transporte para o destino final, por outro lado, ocasiona, também, gastos para o setor público, que acaba absorvendo os custos de disposição final e, em alguns casos, de transporte desse resíduo (Carneiro, Brum e Cassa, 2001), como é o caso de Salvador.

Grande parte do entulho vem do setor informal da construção (pequenas reformas, autoconstrução, ampliações etc.). Avalia-se que o setor formal (indústria da construção civil) contribui com apenas 1/3 do resíduo gerado (Lima e

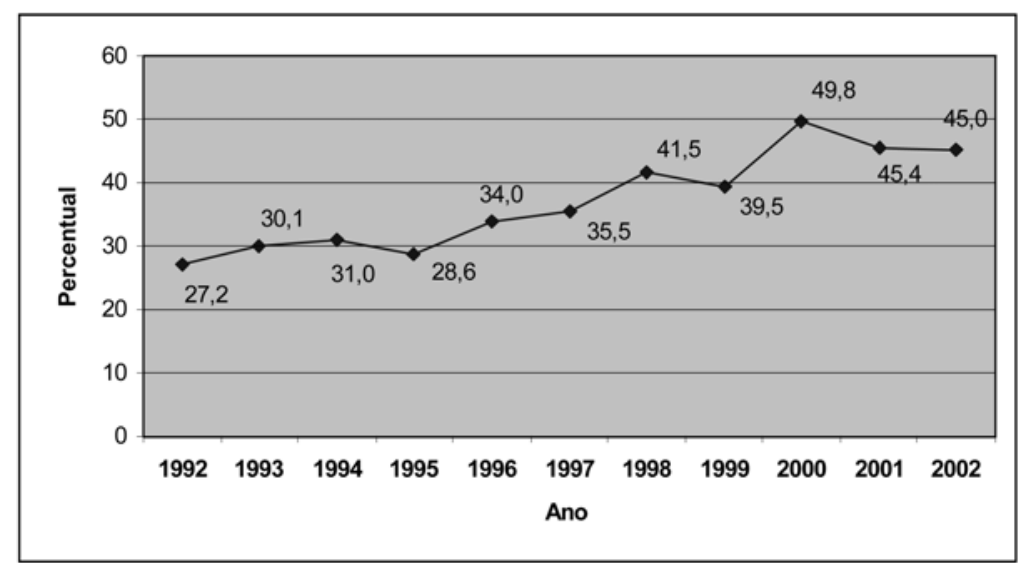

Figura 2 - Evolução da participação de $R C C$ em relação ao total de resíduos coletados em Salvador - 1992/2002

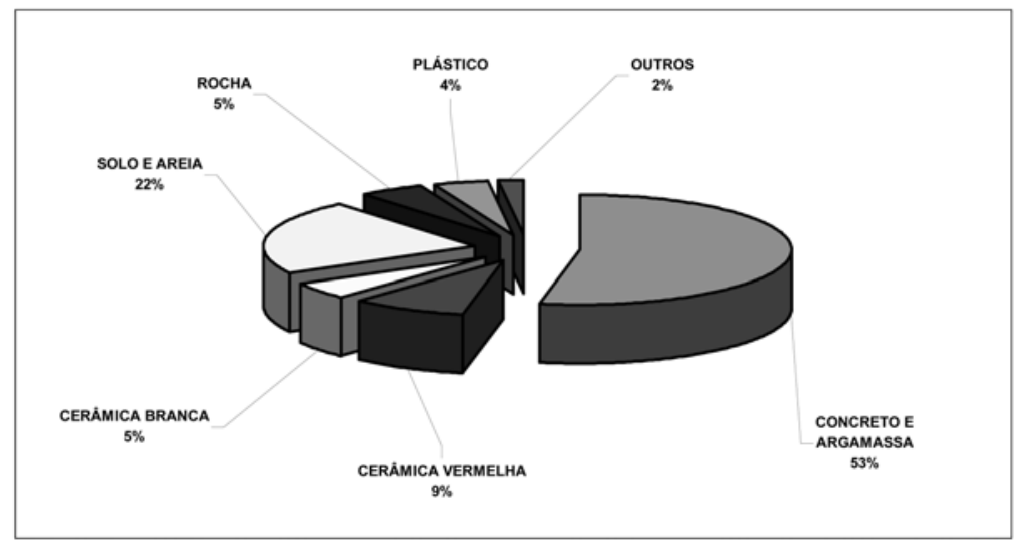

Figura 3 - Composição média de RCC de Salvador - 1999

\footnotetext{
${ }^{6}$ Segundo assessora técnica da LIMPURB (Bonfim, 2003), em 2004, iria funcionar em Canabrava uma escola que deverá formar técnicos na reciclagem de resíduos da construção civil. ${ }^{7}$ A taxa de crescimento do PIB (produto interno bruto) brasileiro em 2001 foi de 1,51\%, bem inferior à de 2000, de 4,46\%. Esse resultado pode ser imputado ao racionamento de energia ocorrido no período e à desaceleração da economia mundial (Cotta e Grabois, 2003).
} 
Tamai, 1998 apud Carneiro, Brum e Cassa, 2001). No caso de Salvador, o RCC transportado por particulares significou cerca de $40 \%$ do total de RCC em 2002, ou seja, eram transportadas, pelo gerador, $1.231 \mathrm{t} / \mathrm{dia}$ de RCC, de forma organizada.

\section{METODOLOGIA}

Este artigo foi produzido basicamente a partir da pesquisa e revisão bibliográfica desenvolvida para a dissertação de mestrado intitulada "Por menos lixo: a minimização dos resíduos sólidos urbanos na cidade do Salvador/Bahia" (Azevedo, 2004), onde os estudos desenvolvidos sobre os RSU no município de Salvador evidenciaram a significativa participação dos resíduos da construção civil na geração total dos resíduos da cidade. Considerou-se oportuno, então, aprofundar o conhecimento sobre o tema, avaliando a forma de gestão dos RCC em uma cidade de tal porte.

Da mesma forma que o referido estudo, a proposta esboçada aqui foi baseada no esquema apresentado por LaGrega, Buckingham e Evans (1994), sobre técnicas de redução da poluição, buscando sua aplicabilidade na gestão dos RCC, para encontrar medidas para a redução de impactos ambientais e degradação de áreas, provocados pelo uso irracional dos recursos naturais, pela intensa geração de resíduos e sua disposição inadequada.

Além da revisão bibliográfica realizada no referido estudo sobre o enfoque preventivo da redução do resíduo na fonte, foi realizada uma análise sobre a legislação relativa aos resíduos da construção civil e sobre as possibilidades de sua minimização na cidade do Salvador.

\section{Parâmetros adotados}

Para fins de demonstração da metodologia adotou-se para a redução na fonte um percentual de $30 \%$ sobre os resíduos gerados, valor que a literatura apresenta como desperdício na obra empresarial (V. Introdução). Esse valor foi distribuído pelas diversas açóes propostas, sendo que alguns percentuais foram definidos aleatoriamente, por não ter sido encontrado, até o momento, um valor norteador:

- mudança nas embalagens - $2 \%$ (aleatório);
- tecnologia de material e ferramental - 2\% (aleatório);

- controle e fiscalização da obra 2\% (aleatório);

- reciclagem na obra - para reaproveitamento dentro da própria obra ${ }^{8}$, adotou-se o valor de $22 \%$ do total de RCC, que corresponde ao percentual de solo e areia dos RCC de Salvador (Figura 4); e

- segregação de resíduos com tratamento definido pela Resolução CONAMA n ${ }^{\circ}$ 307/02: (i) resíduo Classe $\mathrm{C}$ (gesso, tratamento pelo fornecedor) - 0,2\%, baseado na composição do entulho (Figura 4); (ii) resíduo Classe D (perigosos, tratamento pelo fabricante) $1,98 \%$, o valor corresponde a 'outros', na Figura 4, onde, supõe-se estar incluído o resíduo perigoso.

Com relação ao desvio do aterro de inerte e retorno do material ao processo construtivo, foram utilizados os seguintes parâmetros, baseados na segregação dos resíduos para coleta e reaproveitamento diferenciados, segundo as classes estabelecidas na Resolução CONAMA $\mathrm{n}^{\mathrm{o}}$ 307/02 (Brasil, 2003):

- resíduo Classe A (construção e demolição, que deve ser enviado para reciclagem e reutilização) - 72\%, percentual adotado a partir da composição do entulho (Figura 4). Segundo John e Agopyan (2003), essa fração pode ser reciclada como agregado para a produção de concretos estruturais, com encaminhamento dos resíduos de concreto, argamassa, cerâmica e rocha para o aterro de inertes para posterior utilização do resíduo que a usina não tiver capacidade de reciclar;

- resíduo Classe B (plástico, papel, metal etc) $-4 \%$ do total de entulho, percentual adotado a partir da caracterização realizada em Salvador em 1999 (Salvador, 1999). Essa fração deve ser encaminhado à unidade de triagem para comercialização junto com os RSU da cidade;

- implantação de mais 6 postos dos 22 postos previstos no Projeto de Gestão Diferenciada de Entulho, totalizando 12 postos, com a recepção de $200 \mathrm{t} / \mathrm{dia}$ de entulho (os seis PDE receberam quase $100 \mathrm{t} /$ dia de RCC em 2000), o que possibilitaria dobrar a quantidade de RCC que seria utilizado em nivelamento de terreno;
- implantação de mais duas BDE com capacidade de 200t/dia cada, tomando por base o dimensionamento do Projeto de Gestão Diferenciada de Entulho;

- implantação de uma das usinas previstas para aproveitamento de RCC. A capacidade prevista no projeto para cada uma é de 200t/dia;

- como resultado das opçóes de descarte e pela pressão exercida no gerador, a exemplo de cobrança pela disposição e dos programas de educação ambiental, o RCC que segue para o aterro, atualmente, transportado pelo próprio gerador (45\%) passaria para $29 \%$.

Para a disposição em aterro de inertes seriam encaminhados os rejeitos da usina de reciclagem e da reutilização para nivelamento do terreno. Ainda permaneceria seguindo diretamente para o aterro $32,7 \%$ dos resíduos totais, não absorvidos na reciclagem ou reutilização.

\section{OS CAMINHOS PARA UMA GESTÃO SUSTENTÁVEL DOS RESÍDUOS DA CONSTRUCAAO CIVIL EM SALVADOR}

A breve análise da questão dos RCC em Salvador resultou em sugestōes de alternativas para viabilizar a prevenção dos resíduos e de um modelo simplificado para o seu fluxo, visando complementar o Projeto de Gestão Diferenciada de Entulho.

\section{As medidas sugeridas para viabilizar a prevenção dos resíduos}

A Tabela 2 é uma síntese da avaliação do sistema de gestão dos RCC de Salvador a partir do levantamento de pontos positivos e pontos negativos. Sugerem-se medidas para superar cada problema, considerando o enfoque da redução da geração de resíduo.

\section{Modelo simplificado de fluxo para a redução dos RCC}

Considerando que, nas atividades de construção ou reformas, o alto índice de perdas e a ausência de procedimentos de reutilização e reciclagem são as princi-

\footnotetext{
${ }^{8}$ Possibilidade de redução da geração de parte desse resíduo a partir do planejamento e implantação mais cuidadosa dos projetos, evitando cortes excessivos no terreno.
} 
Tabela 2 - Síntese da avaliação da gestão dos resíduos da construção civil de Salvador e medidas possíveis para sua melhoria, visando a minimização na fonte

\begin{tabular}{|c|c|c|}
\hline \multicolumn{2}{|c|}{ Modelo atual } & \multirow[t]{2}{*}{ Medidas sugeridas } \\
\hline Pontos positivos & Pontos genativos & \\
\hline \multirow{5}{*}{$\begin{array}{c}\text { Existe um projeto de gestão } \\
\text { diferenciada de RCC em } \\
\text { implantação, regulamentado pelo } \\
\text { Decreto no } 12.133 \text {, de 8/10/98 } \\
\text { (Regulamento do Entulho). }\end{array}$} & $\begin{array}{l}\text { O projeto não incorpora indicações } \\
\text { para a não geração ou redução da } \\
\text { geração de resíduos e não estabelece } \\
\text { metas para sua implementação }\end{array}$ & $\begin{array}{c}\text { Rever o modelo tecnológico } \\
\text { proposto, incluindo como } \\
\text { prioridade a não geração de RCC. }\end{array}$ \\
\hline & $\begin{array}{l}\text { O projeto foi implantado apenas } \\
\text { parcialmente. O RCC ainda não é } \\
\text { reciclado, sendo encaminhado para } \\
\text { Canabrava. }\end{array}$ & $\begin{array}{l}\text { Concluir a implantação do projeto. } \\
\text { Viabilizar recursos ou incentivar a } \\
\text { iniciativa privada a implantar usinas } \\
\text { de reciclagem de RCC. }\end{array}$ \\
\hline & $\begin{array}{l}\text { Houve um crescimento } \\
\text { extraordinário da geração de } \\
\text { entulho. Quase } 45 \% \text { de RCC é } \\
\text { transportado pelo gerador, que não } \\
\text { paga pela sua disposição. }\end{array}$ & $\begin{array}{l}\text { Responsabilizar o grande gerador de } \\
\text { RCC; passar a exigir mais de quem } \\
\text { faz obras/reformas na cidade. Exigir } \\
\text { plano de bota-fora dos grandes } \\
\text { geradores; introduzir um sistema de } \\
\text { controle nas obras aprovadas na } \\
\text { Prefeitura. Estimular a reciclagem na } \\
\text { própria obra. }\end{array}$ \\
\hline & $\begin{array}{l}\text { A prefeitura absorve cerca de } 56 \% \\
\text { dos custos de transporte de RCC e } \\
100 \% \text { dos custos de disposição. }\end{array}$ & $\begin{array}{c}\text { Introdução de taxas de disposição } \\
\text { para tornar atrativa a reciclagem } \\
\text { interna e/ou externa á obra. Cobrar } \\
\text { pelo transporte e disposição de pelo } \\
\text { menos } 70 \% \text { de RCC gerado. }\end{array}$ \\
\hline & $\begin{array}{l}\text { Houve um crescimento de } 72,30 \% \\
\text { sobre o total de geração de RCC a } \\
\text { partir da implantação do Projeto, ou } \\
\text { seja de } 1997 \text { a } 2002 .\end{array}$ & $\begin{array}{c}\text { Estudar forma de pagar o serviço de } \\
\text { coleta de RCC que desestimule a } \\
\text { sua geração. }\end{array}$ \\
\hline $\begin{array}{l}\text { Foi feita a caracterização do RCC } \\
\text { em } 1999 .\end{array}$ & $\begin{array}{c}\text { Não se adota uma periodicidade } \\
\text { para realizar a caracterização desse } \\
\text { resíduo. }\end{array}$ & $\begin{array}{c}\text { Fazer regularmente a caracterização } \\
\text { do entulho, tendo como parâmetro } \\
\text { a classificação contida na Resolução } \\
\text { CONAMA no 307/02. }\end{array}$ \\
\hline
\end{tabular}

pais causas da geração de resíduos, sugere-se um modelo de fluxo que, aliado às medidas vistas anteriormente, pode fornecer à administração municipal um instrumental capaz de exercer pressão no gerador, no sentido de estimular a redução do desperdício na obra, responsabilizando-o, também, pela segregação dos resíduos na fonte e pelo transporte e disposição adequada dos resíduos restantes. Por sua vez, o gerador pode vir a pressionar a indústria no sentido da adequação a um novo paradigma de fabricação de material e ferramental de construção.

A proposta tomou por base três estratégias, situadas em níveis de hierarquia distintos, ilustrados na Figura 4: (i) prevenção; (ii) desvio do resíduo da disposição em aterro; e (iii) disposição em aterro de RCC. A Figura 4 indica que, para a direita e para baixo, o enfoque vai se encaminhando para as tecnologias fim-detubo ${ }^{9}$, ou seja, as práticas tornam-se menos adequadas ambientalmente. Na parte superior está esclarecido o tipo de atividade correspondente a cada ação. O fluxo sugerido na Figura 4 apresenta quantitativos como um exercício para estimar uma possível redução.

A redução na fonte inclui o reuso de produtos e a reciclagem interna. É considerada redução na fonte quando o resíduo não entra no "fluxo dos resíduos" do sistema de limpeza urbana da cidade, ou seja, não envolve gastos com transporte, reciclagem, tratamento ou disposição final.

A prevenção da geração dos resíduos por meio da redução na fonte geradora (construção ou reforma) envolve medidas para a promoção:
- do desenvolvimento tecnológico, a partir de pressōes do gerador para que as indústrias pesquisem melhores embalagens para os produtos, melhores tecnologias para os materiais de construção e ferramental;

- de boas práticas operacionais, na medida em que preconiza uma melhor gestão de processos e das práticas gerenciais, controle e fiscalização da obra, reciclagem dentro da própria obra (evitando que o resíduo entre no fluxo do sistema da cidade), prevenção de perdas de material, melhoria da condição de estoque e transporte, utilização de ferramentas adequadas;

- do planejamento da obra, com o aperfeiçoamento de projetos, seleção adequada de materiais, treinamento de re- 
cursos humanos, programação das etapas da obra, paginação de revestimentos e pisos, modulação de produtos;

- da taxação da geração de resíduos, com a cobrança pela quantidade de resíduos a ser disposta nas bases de descarte e no aterro;

- de campanhas educativas, para sensibilizar os geradores à redução de resíduos.

A segunda estratégia, que consiste no desvio do resíduo da disposição em aterro e reincorporação ao processo construtivo como matéria-prima para produção de materiais de construção, evitando o uso de recursos naturais (muitas vezes, não renováveis), promove:

- a segregação dos resíduos em correntes de resíduos, segundo as classes estabelecidas pela Resolução CONAMA $\mathrm{n}^{\circ} 307 / 02$, visando a coleta e tratamentos diferenciados;

- o reaproveitamento do RCC por meio da reciclagem, tomando por base o Projeto de Gestão Diferenciada de Entulho, que ainda não foi totalmente implantado, e estabelecendo metas para sua viabilização.

Por fim, a disposição em aterro de inertes dos resíduos restantes, quando não for possível uma das soluçóes anteriores, partindo, porém, de um novo enfoque, segundo o qual, o aterro deverá funcionar como local de armazenamento para posterior utilização.

\section{CONCLUSÃO}

No exemplo do modelo citado, consegue-se uma redução da geração dos RCC, pré-estabelecida, de $30 \%$, um desvio do aterro de inertes de $37,3 \%$, ou seja, 807t/dia de RCC reciclado ou reutilizado para nivelamento de terreno, e o encaminhamento para o aterro de inertes de 32,7\% do RCC gerado.

A redução seria obtida a partir de uma melhor embalagem dos produtos, melhoria da tecnologia dos materiais e ferramental de construção, controle e fiscalização da obra, capacitação da mãode-obra e reciclagem dentro da própria obra, evitando que o resíduo entre no fluxo dos resíduos urbanos.

$\mathrm{O}$ aproveitamento de RCC dar-seia por meio da sua separação nas classes definidas pelo CONAMA, com encaminhamento para os tipos correspondentes de solução - reciclagem e reutilização do material de demolição e comercializa ção do material tipo plástico, $\mathrm{papel} / \mathrm{pa}$ pelão etc, que seriam encaminhados para a Cooperativa de Agentes Autônomos de Reciclagem (COOPCICLA). O RCC não reciclado seria encaminhado para o aterro de resíduos da construção civil, como estabelece a Resolução CONAMA $\mathrm{n}^{\circ} 307 / 02$ "de forma a possibilitar seu uso futuro e/ou futura utilização da área" (Brasil, 2003, p.1), tendo sempre em vista, entretanto, evitar esse tipo de solução fim-de-tubo.

As medidas sugeridas são sintetizadas a seguir:

- medidas regulatórias ou de controle - rever a regulamentação municipal, complementando-a para não permitir que o RCC seja depositado em aterro domiciliar, já levando em consideração a Resolução CONAMA n ${ }^{\circ}$ 307/02;

- medidas econômicas - introduzir a taxa de deposição de RCC para tornar atrativa a reciclagem interna e/ou externa à obra; cobrar pelo transporte e disposição de pelo menos $70 \%$ do RCC gerado;

- medida de acompanhamento e controle - fazer regularmente a caracterização do RCC, tendo como parâmetro a classificação contida na referida resolução;

- medidas de gestão - concluir a implantação do Projeto de Gestão Diferenciada de Entulho, viabilizar recursos ou incentivar a iniciativa privada a implantar usinas de reciclagem; passar a exigir mais de quem faz obras/reformas na

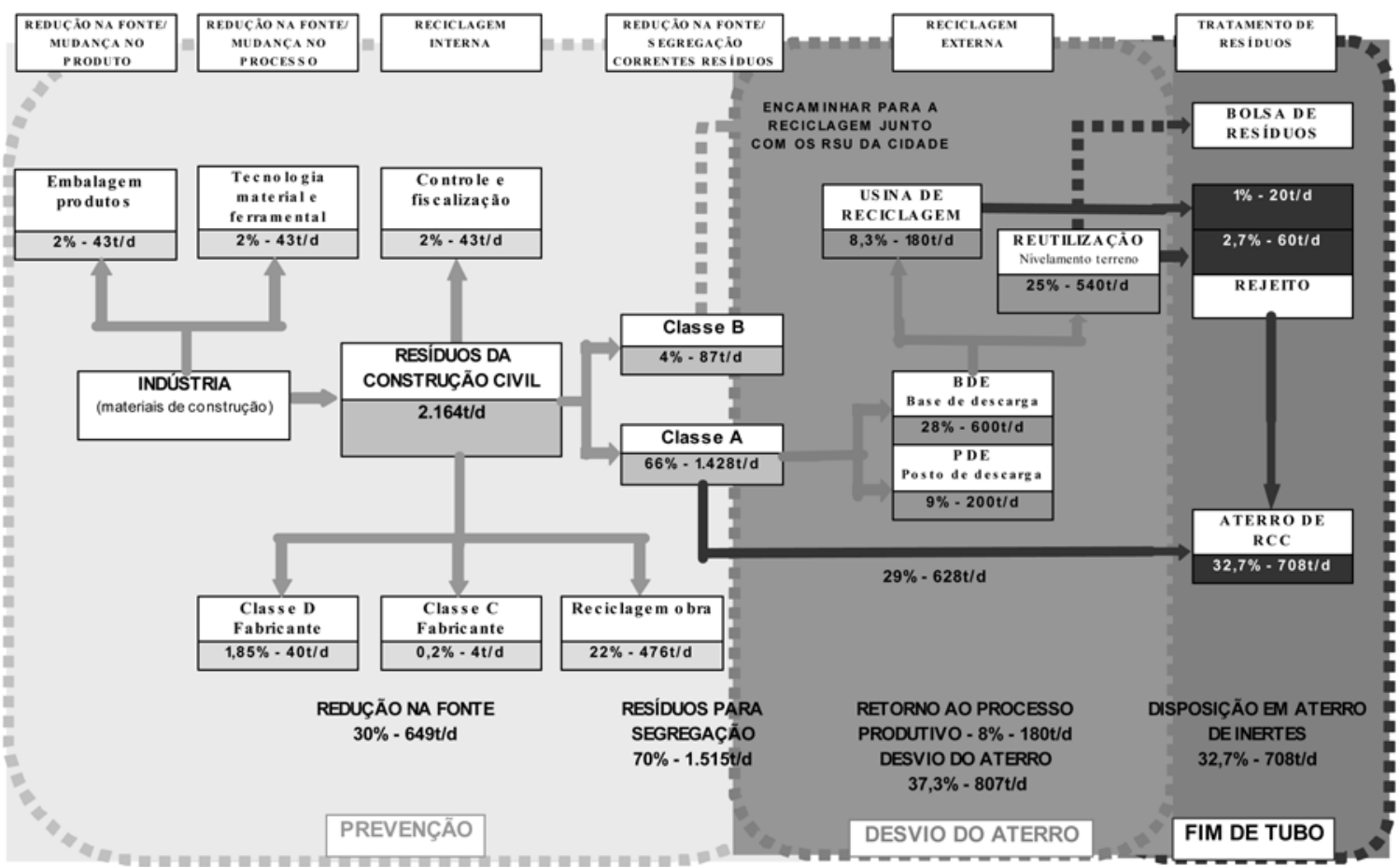

Figura 4 - Modelo de fluxo para a redução da geração de resíduos da construção civil de Salvador 
de controle nas obras aprovadas pela Prefeitura;

- medida de caráter social - promover a sensibilização dos segmentos envolvidos na questão, de forma a estimular a redução do desperdício na obra, treinamento da mão-de-obra com ênfase nesse enfoque.

Considera-se que a Resolução CONAMA n ${ }^{\circ}$ 307/02 facilitou a reorientação da gestão dos RCC e viabilização de medidas que assegurem um melhor desempenho da construção civil, direcionadas para o enfoque da prevenção da geração de resíduos.

A reciclagem, interna e externa à obra, parece ser viável tanto do ponto de vista técnico como ambiental, sugere-se, no entanto, o desenvolvimento de pesquisas para consolidar em definitivo soluçōes para o reaproveitamento dos RCC. A educação/sensibilização e informação aos grandes e pequenos geradores poderão se constituir em apoios importantes para a implementação de um programa com o enfoque na prevenção e redução dos desperdícios na obra.

Finalmente, considerando-se que cada vez existe menos espaço para a convivência com tão elevado índice de perdas e com o desperdício de recursos naturais, sugere-se que sejam realizadas pesquisas sobre os índices de perdas na construção civil para os vários tipos de construção, incluindo a construção informal, para que se possa dispor de dados consistentes para viabilizar a gestão sustentável dos resíduos da construção civil.

Espera-se que esse exercício possa contribuir para pesquisas mais detalhadas sobre a questão e que aponte um caminho na busca da prevenção da poluição, em uma sociedade mais preocupada com soluções viáveis ambientalmente $\mathrm{e}$ que não se dispõe a pagar por custos que representam desperdícios e que decorrem de inadequados sistemas de gestão.

\section{REFERÊNCIAS}

ADAM, R.S. Princípios do ecoedificio: interação entre ecologia, consciência e edifício. São Paulo: Aquariana, 128p. 2001.

AZEVEDO, G. O.D. Por Menos Lixo: A minimização dos resíduos sólidos urbanos na cidade do Salvador/Bahia. Dissertação (Mestrado em Engenharia Ambiental Urbana) - Escola Politécnica, Universidade Federal da Bahia, Salvador. 163 f. 2004.

BLOISI, R. F. M. Análise do gerenciamento do sistema de limpeza urbana de Salvador/Bahia: avanços e desafios para sua sustentabilidade.
Monografia (Especialização em Gerenciamento e Tecnologias Ambientais na Indústria) - Escola Politécnica, Universidade Federal da Bahia, Salvador. 127f. 2002.

BONFIM, J. Entulho de construção vai ter coleta seletiva: resolução do Conselho de Meio Ambiente enquadra os geradores de lixo. A Tarde, Salvador, segunda-feira, 6 out. 2003.

BRASIL. MINISTÉRIO DO MEIO AMBIENTE. Resolução CONAMA n. 307, de 5 de julho de 2002. Estabelece diretrizes, critérios e procedimentos para a gestão dos resíduos de construção civil. Diário Oficial da União, Brasília, DF, 17 jul. 2002. Disponível em: <http://www.mma.gov.br/ conama> Acesso em: 29 jul. 2003.

CARNEIRO, A. P. et al. Caracterização do entulho de Salvador visando a produção de agregado reciclado. In: VIII ENCONTRO NACIONAL DE TECNOLOGIA DO AMBIENTE CONSTRUIDO, 2000, Salvador-BA. Anais. Salvador: ANTAC, v II p. 932. 2000.

BRUM, I.A.S.; CASSA, J.C.S. (org.).

Reciclagem de entulho para a produção de materiais de construção: projeto entulho bom. Salvador: EDUFBA; Caixa Econômica Federal, 312p. 2001.

COTTA, E.; GRABOIS, P. PIB brasileiro somou $R \$ 1,184$ tri em 2001. Folha on line. São Paulo, 29 mar. 2002. Disponível em: www.frigoletto.com.br Acesso em: 31 out. 2003.

JOHN, V. M.; AGOPYAN, V. Reciclagem de residuos da construção. In: SEMINÁRIO RECICLAGEM DE RESÍDUOS DOMICILIARES, São Paulo. Disponível em: www.reciclagem. pcc.usp.br . Acesso em: 12 ago. 2003.

KIPERSTOK, A. et al. Prevenção da poluição. Brasília: SENAI/DN, 290p. 2002.

LAGREGA, M.D.; BUCKINGHAM, P. L.; EVANS, J. C. The environmental resources management group. Harzadous waste management. 1 ed. Singapore: McGraw-Hill International Editions, 1146 p. 1994.

PINTO, T. P. Metodologia para a gestão diferenciada de resíduos sólidos da construção urbana. Tese (Doutorado em Engenharia da Construção Civil) - Escola Politécnica, Universidade de São Paulo, São Paulo. Disponível em: www.reciclagem. pcc.usp.br . Acesso em: 12 ago. 2003. 189 f. 1999.

RESÍDUOS DE CONSTRUÇÃO E DEMOLIÇÃO. FATOS E NÚMERO. Disponível em: <http://www.reciclagem.PCC.usp >. Acesso em: 12 ago. 2003.

SALVADOR. Decreto n. 12 133, de 8 de outubro de 1998. Dispóe sobre o resíduo das obras da construção civil. Diário Oficial do Município, Salvador, 9 out. 1998.

SALVADOR. SESP. LIMPURB. Gestão diferenciada do entulho na cidade do Salvador (relatório final). Salvador, 136p. 1997.

Relatório anual de atividades: documento interno. Salvador, 2002.

Relatório anual de atividades: documento interno. Salvador, 1999. Relatório anual:

documento interno. Salvador, 1996.
SANTANA, A.. Maior parte do entulho ainda é depositada nas vias públicas: legislação municipal prevê pesadas multas para quem insiste e apud $m$ sujar a cidade. Correio da Bahia, Salvador, Aqui Salvador, 28 mar. 2003.

THORPE, B. Citizen's guide to clean production: clean production network. Massachusetts: University of Massachusetts Lowel, 47 p. 1999.

USP. A construção civil e o meio ambiente: meio ambiente, um grande problema. Textos técnicos. Disponível em: www.reciclagem.pcc.usp.br. Acesso em: 14 ago. 2003.

\section{Endereço para correspondência:}

\section{Gardênia Oliveira David de \\ Azevedo}

Dep. de Engenharia Ambiental

Universidade Federal da Bahia

Rua Prof. Aristides Novis, 2 - $4^{\circ}$

Andar

402 I0-910 Salvador - BA- Brasil

Tel.: (7I)343 I-0869 - 3235-4436

E-mail:gardenia.azevedo@terra.com.br 